\title{
Commentary
}

\section{Endo-bariatrics: Are we ready?}

\author{
Sundeep Lakhtakia
}

Asian Institute of Gastroenterology, Hyderabad, Telangana, India

Obesity and malnutrition are at opposite ends of the nutritional health spectrum. The nutritional balance world over in recent decades has heavily tilted in favor of former, starting from the developed nations to the developing world, and India is no exception. Professional organizations classify obesity, defined as a body mass index (BMI, the weight in kilograms divided by the square of the height in meters) of 30 or higher, as a disease. ${ }^{[1]}$ People who are overweight or obese account for more than two-thirds of the U.S. population. ${ }^{[2]}$ In absolute term, three countries - USA, China, and India - contribute to $>50 \%$ of world obese patients. ${ }^{[3]}$ The prevalence of obesity in India is increasing continuously, and a recent report reveals that between $13 \%$ and $50 \%$ of the urban population and $8 \%$ and $38 \%$ of the rural population suffer from obesity. ${ }^{[4]}$

Factors favoring a positive energy balance and weight gain, i.e., obesity, include increasing per capita food supplies and consumption, particularly of high-calorie, palatable foods that are often served in large portions; decreasing time spent in occupational physical activities; and displacement of leisure-time physical activities with sedentary activities such as television watching and use of electronic devices. Lifestyle changes (lack of physical activity, dietary alterations) have predominantly been responsible for the rise of obesity epidemic. Genetic predisposition to obesity also plays a role to some extent.

The healthcare afflictions associated with obesity involve almost all organ systems - coronary artery disease, hypertension, liver involvement (fatty liver, nonalcoholic steatohepatitis, and cirrhosis), obstructive sleep apnea, esophagus (gastroesophageal reflux disease, Barrett's esophagus, and esophageal adenocarcinoma), diabetes mellitus, risk of malignancy (pancreas, colon), osteoarthritis, etc., are some to name a few, apart from psychological impact. The economic impact involved to

Address for correspondence: Dr. Sundeep Lakhtakia, Asian Institute of Gastroenterology, Somajiguda, Hyderabad, Telangana, India. E-mail: drsundeeplakhtakia@gmail.com

This is an open access journal, and articles are distributed under the terms of the Creative Commons Attribution-NonCommercial-ShareAlike 4.0 License, which allows others to remix, tweak, and build upon the work non-commercially, as long as appropriate credit is given and the new creations are licensed under the identical terms. individual and healthcare agencies in managing each one of the ailments is tremendous. This situation becomes even more burdensome for Indian context, where cost of treatment is majorly borne by individual alone, and public health is either suboptimal or commercial health insurance is available to minority.

"Prevention is better than cure" is an age-old saying, and obesity best fits into it. However, in spite of best efforts from obese subjects by "exercising" and "dieting," the problem of obesity does not always easily subside. It needs constant motivation for months and years to observe objective improvement and maintenance.

Moderate weight loss, defined as a $5 \%-10 \%$ reduction in baseline weight, is associated with clinically meaningful improvements in obesity-associated disorders, e.g., a 5\% weight loss improves pancreatic beta-cell function and the sensitivity of liver and skeletal muscle to insulin, thereby improving diabetes along with its collateral benefits.

Efforts in reducing obesity with medicines have been lead to limited and temporary success. Hence, a variety of surgical procedures/interventions - both open and laparoscopic - e.g., sleeve gastroplasty, Roux-en-Y gastric bypass, laparoscopic adjustable gastric band, and biliopancreatic diversion, have gone through modifications and now been found to effective in rapid and sustained reduction in body weight and BMI. However, bariatric surgery is invasive, irreversible and may have short- and long-term adverse events.

Interventional endoscopic procedures (endobariatrics) arrived relatively late in the scene and added novelty by their minimally invasive nature. The initial interventions included gastric balloon (reduce gastric capacity), duodenojejunal bypass liner, or endoscopic sleeve (malabsorptive device). Gastric

\begin{tabular}{|l|l|}
\hline \multicolumn{2}{|c|}{ Access this article online } \\
\hline Quick Response Code: & \\
\hline
\end{tabular}

How to cite this article: Lakhtakia S. Endo-bariatrics: Are we ready? J Dig Endosc 2018;9:181-2. 
balloons from various companies show early reduction in BMI; however, sustained effect is often missing mainly due to their finite indwell. The new endoscopic intervention - endoscopic sleeve gastroplasty (ESG) - reduces the stomach capacity and reservoir function of fundus by durable endoscopically suturing (both full thickness and submucosal) of the anterior and posterior gastric wall along the greater curve leaving a narrow gastric tube. The end result - both anatomically and physiologically - reduces the gastric capacity which improves satiety and delays gastric emptying-mimicking surgical sleeve gastroplasty. The procedure is popular in western world with reasonable safety and efficacy.

Nitin et al.,${ }^{[5]}$ in their initial experience, report the benefits of ESG to reduce the obesity. The endoscopic bariatric interventions have to keep pace with increasing prevalence of obesity. With the wider usage of endobariatrics in
India, the interventions are likely to become cost-effective as safety is ensured with rising experience. Health insurance companies would also find merit in approving these procedures due to collateral health benefits.

\section{REFERENCES}

1. AMA Adopts New Policies on Second Day of Voting at Annual Meeting. Press Release of the American Medical Association; June 18, 2013. Available from: http://www.npr.org/ documents/2013/jun/ama-resolution-obesity.pdf.

2. Health, United States, 2015: With Special Feature on Racial and Ethnic Health Disparities. Hyattsville, MD: National Center for Health Statistics; 2016. p. 461.

3. Karri S, Sharma S, Hatware K, Patil K. Natural anti-obesity agents and their therapeutic role in management of obesity: A future trend perspective. Biomed Pharmacother 2018;110:224-38.

4. Misra A, Shrivastava U. Obesity and dyslipidemia in South Asians. Nutrients 2013;5:2708-33.

5. Jagtap N, Kalapala R, Katakwar A, Darishetty S, Reddy DN. Endoscopic sleeve gastroplasty for obesity - first indian experience: case series and review of literature. J Digestion Endosc 2018;4:165-7. 